\title{
Cultural Entrepreneurs and Creating Exchange
}

\author{
Nicholas Wilson \\ David Stokes \\ Kingston University \\ Kingston Business School \\ Kingston upon Thames, Surrey, U.K.
}

\begin{abstract}
Marketing, as it relates to the arts, is not about intimidation or coercion or abandoning an artistic vision. It is not 'hard-selling' or deceptive advertising. It is a sound, effective technology for creating exchanges and influencing behaviour that, when properly applied, must be beneficial to both parties involved in the exchange" (Kotler and Scheff, 1997). The focus of this paper is on how owners / managers of small and medium sized Independent businesses in the music industry ('cultural entrepreneurs') create exchange and influence behaviour when accessing finance for their businesses. The paper is based on Leadbeater and Oakley's (1999) description of a 'new' model of work and creative production, derived from cultural entrepreneurs' characteristic 'independence'. With reference to initial findings from a major Government-sponsored research project looking at the extent to which access to finance acts as a barrier to growth for small and medium-sized enterprises (SMEs) in the Music Industry, the paper identifies some potential difficulties such independence might lead to in creating beneficial exchange. The importance of appropriate partnership and promotion strategies, effective communication skills, and financial self-sufficiency are highlighted in the context of the Industry's uncertain environment. In conclusion, it is argued that the reconciliation of the entrepreneurs' independence on the one hand with the qualities that allow mutually beneficial exchange on the other, is a primary requisite for effective cultural entrepreneurship.
\end{abstract}

\section{INTRODUCTION}

The contribution of 'cultural entrepreneurs' to the vitality and health of the country has gained increasing recognition in recent years. Over and above their role in generating new jobs and economic growth (twice that of the economy as a whole), and in promoting social cohesion and a sense of belonging, they have been seen as providing a 'new' model of work and creative production ${ }^{1}$. To a significant extent this new model has been built on the technological advances that have spawned the ever-wider access to computers and the Internet. In the case of the music industry, the advent of

\footnotetext{
${ }^{1}$ see Leadbeater, C. and Oakley, K. (1999) The Independents
} 
digital distribution, or 'the juke box in the sky', offers huge opportunities as well as threats. The significant entrepreneurial role of SMEs in the music industry has been emphasised by the emergence of on-line music businesses using new technologies. Brindley (2000) argues that music entrepreneurs are creating new business models of music distribution in which "the ultimate end game is the seamless delivery of music - anywhere, anytime and through any media”. It is against this background of opportunity that the Department for Culture, Media and Sport commissioned the Small Business Research Centre, Kingston University to investigate the extent to which access to finance acts as a barrier to growth for SMEs in the music industry. The first part of this research involved an extensive literature review, followed by 28 in-depth interviews with Industry practitioners and experts. Whilst additional research includes a quantitative analysis of over three hundred music businesses in relation to finance and growth, this paper uses the research's initial findings to shed new light on entrepreneurial activity in this industry.

\section{THE UK CULTURAL SECTOR}

It is helpful to consider some of the main characteristics of the cultural sector, prior to discussing the music industry in more detail. The UK is arguably the most deregulated of all European Member State economies and the characteristics of cultural employment reflect this ${ }^{2}$. Permanent employment is only typical in the UK museums and heritage sub-sector, whilst in publishing, fixed-term contracts now equal permanent employment. Freelancing and self-employment are the most frequent types of employment in the sector. The recent report on Business Assistance \& Financial Investment Services on Merseyside (Euclid, 1999), puts forward a number of further characteristics which typify the arts and cultural sector:

o There are a large number of small enterprises (less than 10 employees) and sole traders, (all referred to here as 'cultural entrepreneurs') - and these numbers are growing

o There is a small but significant number of large enterprises

o There are particularly large concentrations of very small enterprises and sole traders in music, the performing arts, TV, film \& radio, and design

0 There is income generation across a number of areas, including grants, sales/box office and commission/fees

o The majority of businesses (excluding sole traders) in the sector have an income from arts and cultural activity of less than $£ 50,000$ - and very many have an income of less than $£ 25,000$

\footnotetext{
${ }^{2}$ Hackett \& Ramsden (2000) The Employment and Enterprise Characteristics of the Cultural Sector in Europe
} 
Furthermore, the UK's cultural sector is unevenly distributed, with $29 \%$ of those working in the cultural industries in 1995 residing in London (Arts Council of England, 1995). An "hour-glass effect", whereby there are concentrations of people employed in a small number of large enterprises, and a large number of very small ones, has been identified (Hackett \& Ramsden, 2000). All sub-sectors show a continuing "narrowing” in the hour-glass neck, suggesting that employment amongst medium-sized enterprises is in decline across the cultural industries.

\section{CULTURAL ENTREPRENEURSHIP AND THE MUSIC INDUSTRY}

Before examining the new model of work attributed to cultural entrepreneurs, this paper considers what and who we mean when using the term in the context of 'the music industry'.

In presenting the findings of the recent NMC's report on the economic value of music to the United Kingdom, it was noted that "if you are unable to identify the industry, then you cannot shout about it" (Westall and Cowling, 1999). Given the sometimes public tensions that exist between different stakeholders within the music industry, principally between artists and record companies (e.g. George Michael and Sony), and between record companies themselves (i.e. the Majors and Independents), it is all the more important to clearly identify whose interests are being included when referring to the 'music industry' per se. This is important at the policy level - some recent reports focus squarely on the artists and musicians at the creative edge (Musicians' Union, 2000); Greaney, 2000) etc., at music businesses (DCMS, 2000), or a mixture of both (National Music Council, 1999; Merseyside Music Development Agency, 1999) - but also in understanding how mutually beneficial exchange can take place between cultural entrepreneurs, artists and other service providing businesses.

There is no consensus as to precisely what types of businesses are representative of the 'music industry'. At the broadest level, the music industry can be seen to encompass all activities and businesses that have music as product. This all-embracing definition of the music industry is as diverse as the music composed, performed and recorded. It includes the creators, developers, packagers, marketers, distributors and advisors, who together add value to the music product on its journey to the end-user - the consumer. It constitutes both 'commercial' popular music and the 
predominantly not-for-profit, subsidised classical music sector ${ }^{3}$. Taking a cultural perspective, we might consider all musicians, however modest their abilities, to have a place within the music industry. From an economic perspective, however, we are faced by the often 'invisible' contribution made to the industry by many individuals whose activities are not recognised formally within a business context. Self-employed freelance musicians make up a sizeable part of the industry by employment, if not by income and sales generated. Very often, these become the cultural entrepreneurs that, having worked as musicians themselves, take their artistic vision into new realms and establish businesses to provide services to other musicians.

Despite the range of activities, there is a logical rationale behind grouping music businesses under an industry heading. This can be seen in the context of the value chain that links the "three-tiered existence" of a music industry product from composer/musician to consumer. All stages of the chain are necessary for producing the music product that the end-user is willing to pay for. Depending on whether the music is to be experienced through live performance or through recorded format, however, there are a variety of different businesses involved in the process of adding value:

For the purposes of this research, the three central activities of 'development', 'packaging' and 'marketing' are of particular interest. This incorporates the major value-adding (entrepreneurial) business activities of record production, music publishing, artist management, concert promotion, recording services, and some aspect of online music services ${ }^{4}$. Cultural entrepreneurs within the music industry are very often involved with more than one of these activities, and so the sectoral boundaries must be treated with some caution. Many record labels have some kind of music publishing activity, for instance. In addition, 'online music services' can be seen to include businesses in a number of the other sectors, as well as retail and distribution ${ }^{5}$.

\footnotetext{
${ }^{3}$ In the music industry there has been a clear polarisation into the five large, global corporates (EMI, the only British owned company; Universal Music Group; Sony; Warner Music Group, and BMG) who together account for over three quarters of industry turnover, and the smaller, but far more numerous independents.

${ }^{4}$ It is noted that most online music services are concerned with retail / distribution and therefore are not central to this study. Creation and Distribution are also not included within this study.

${ }^{5}$ The National Music Council produced a comprehensive report on the economic value of music to the United Kingdom - "A Sound Performance” (1999) - which the authors would recommend reviewing for more detailed information in this area
} 
Exhibit One: The Value Chain of the Music Industry (Sound Carriers \& Performance) Source: Sibelius Academy, 1998

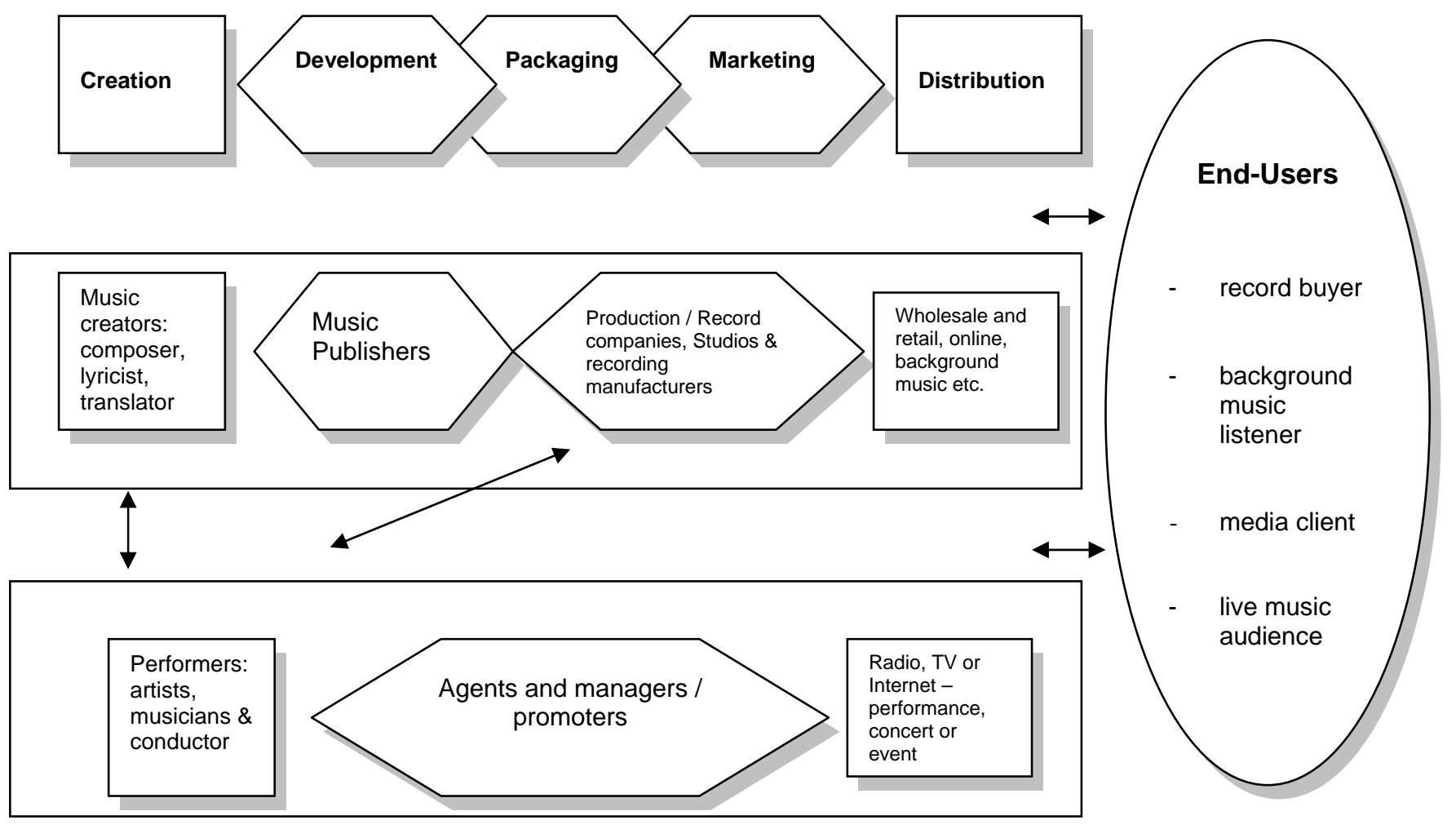

\section{CULTURAL ENTREPRENEURS - HOW THEY WORK?}

In line with most if not all entrepreneurs, those working in the cultural arena are 'independent' in character, working according to their own beliefs and at their own pace. This independence has been seen as integral to the fostering of entrepreneurial innovation and creativity. It has also given rise to a 'new' model of work being identified, which consists of four key ingredients ${ }^{6}$ :

(i) A blurring of the demarcation line between consumption and production. Creativity is seen as usually an incremental development that "modifies and adapts what has gone before". In this regard, "to be a creative producer it helps to be an avid consumer".

(ii) A blurring of the demarcation line between work and non-work. Many cultural entrepreneurs say that their best ideas come to them when

\footnotetext{
${ }^{6}$ Leadbeater, C. and Oakley, K. (1999) p.24-25
} 
they are not at work. Leadbeater and Oakley state "Finding and justifying this 'down -time is critical to any creative business. This carries lessons for larger businesses that pride themselves on punishing work schedules for executives that leave little room for thinking and creating new ideas”.

(iii) The combination of individualistic values with collaborative working. Whilst cultural producers often have core skills that are central to the creative process (e.g. a song-writer or performing musician), "they recognise their particular skill is next to useless unless it can be combined with the skills of others... They expect to work in teams”.

(iv) Being members of a wider creative community. "They induce a process of intense rivalry and competition as well as promoting cooperation and collaboration”.

In terms of understanding how an independent approach to work might affect the cultural entrepreneurs' ability to create beneficial exchange, it was necessary to analyse such an exchange in more detail. The Kingston Business School research on access to finance in the music industry offered the opportunity for this. Whilst from the music business's perspective, finance may be regarded as principally an enabler as opposed to the endproduct, the exchange concerned is based on 'content' for 'service'. This exchange is repeated between artists and their managers, record companies, publishers, promoters, recording companies and the like. It is also, of course, the principal exchange that dominates the dot.com 'revolution'. As such, it would seem an appropriate exchange to analyse. The following section provides some background to the nature of the analysis carried out in the form of in-depth interviews.

\section{METHODOLOGY}

Given the strong collective public identity of the music industry, it seemed especially important to understand the extent to which widely held perceptions about the industry's ability, or otherwise, to create exchanges, influence behaviour positively, and to therefore access finance, were sustained in reality. The use of in-depth interviews has been seen to be particularly helpful in situations where research seeks to learn the consensus meanings ascribed by a group of people to their experience and to articulate the thematic relationship expressed in this meaning system (Smircich, 1983). Holding in-depth interviews therefore represented the first stage in determining what industry perceptions were foremost in stakeholders' minds. 
It was originally envisaged to carry out 15 interviews with key informants from both the music industry and from finance providers ${ }^{7}$. However, in the course of the research it became clear that in order to provide as rich and informative picture as possible, it would be necessary to interview more than this number. This was justified on the basis that the diversity of businesses that make up the six sectors of the industry demanded a wider range of views and opinions to be heard.

The sampling groups themselves were drawn up to include representatives of the main trade associations (including the BPI, AIM, MPA, MMF, CPA, APRS and e-DIMA), as well as cultural entrepreneurs from each of the six sectors under review. Representatives of High St. banks, specialist banks, Venture capitalists, and other professional service providers (music industry accountants / lawyers) were included to offer the 'other' side of the story. Interviews were recorded on audio cassette and transcribed subsequently in full $^{8}$. Semi-structured interview plans were prepared prior to the interviews themselves, allowing for a degree of 'informality' within the interview, where particular issues of interest could be explored in more detail. Interviews usually lasted between forty-five minutes and one hour. Content analysis of the transcripts was carried out manually, with particular reference to the four ingredients of cultural entrepreneurial work outlined above.

\section{RADICAL UNCERTAINTY AND THE MUSIC BUSINESS}

Uncertainty is a fact of life for all businesses, big and small. Whilst larger businesses may be able to offset uncertainty through their abilities to influence their business environment, smaller businesses tend to be more vulnerable to this fact of business life. Initial findings of this research suggest that within the music industry there exist generic small business finance issues which contribute to the level of uncertainty experienced, (e.g. unwillingness to trade ownership for equity, information asymmetry, or inability of younger firms to provide level of security required by lender). In addition, there is a range of factors that when experienced together give rise to what can be seen as 'radical uncertainty' in the face of technological and social change:

o UNCERTAINTY diminishes trust / confidence in creating exchange across the music industry value chain

\footnotetext{
${ }^{7}$ The client (DCMS) put forward a list of eleven initial contacts, all of whom were subsequently interviewed

${ }^{8}$ In two cases, the interviewee refused to be recorded and detailed notes were taken during the interview, and written up immediately afterwards
} 
o Relevance of different factors contributing to UNCERTAINTY will vary depending on stage of development (start-up; development)

0 A range of factors in the music industry (over and above the generic issues that all small businesses face) conspire to create RADICAL UNCERTAINTY

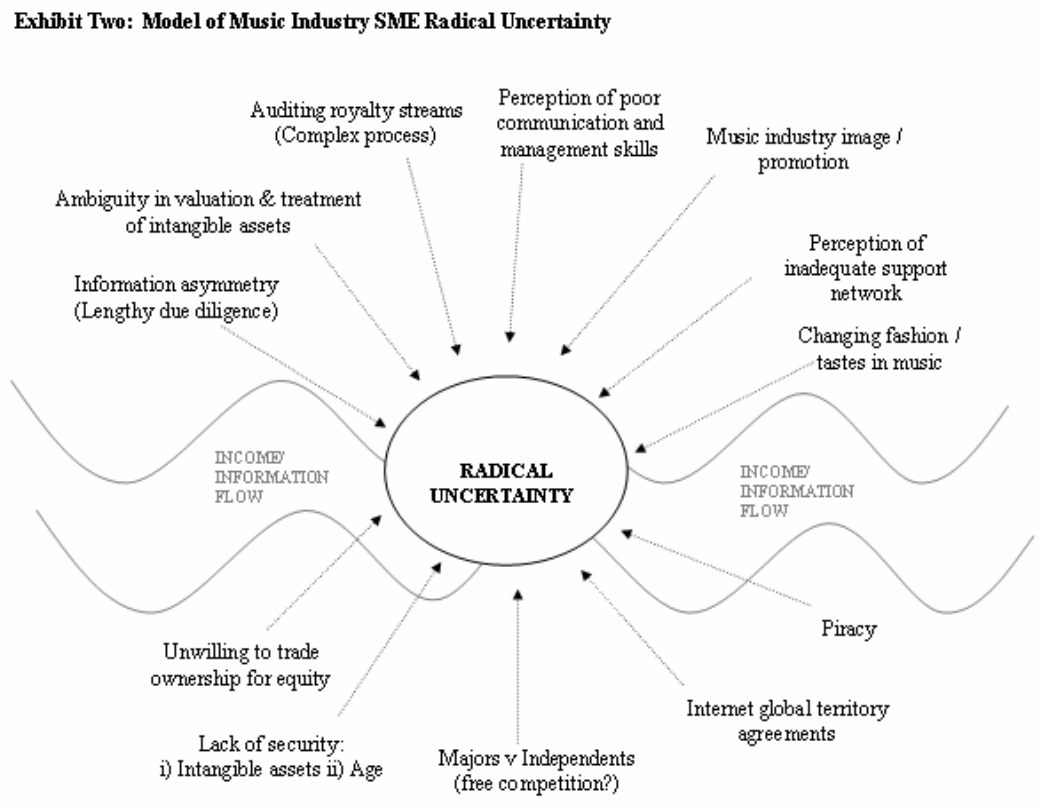

\section{CULTURAL ENTREPRENEURS AND CREATING EXCHANGE}

This paper argues that each of the four ingredients of cultural entrepreneurial work, described above, also contribute in some way to this radical uncertainty. The research undertaken provides some pointers towards reconciling cultural entrepreneurs' independence of spirit with those qualities that allow mutually beneficial exchange to take place. The findings are discussed in relation to each of the four ingredients.

\section{(i) A blurring of the demarcation line between consumption and production}

Whilst creativity has been described as an incremental process, often derived from other people's creativity, the extent to which the cultural entrepreneur is both producer and consumer is perhaps more complicated that at first it would appear. From a marketing standpoint, many theorists maintain that a basic premise of the marketing concept is that a company should determine 
what consumers need and want, and try to satisfy those needs and wants. Some writers have pointed to the apparent inherent inconsistency of this philosophy, however, with what "the concept of art is all about"9. The music businesses' perceived focus on artists as "customers" derives from the Industry's naturally prevalent "product" focus. The "Art-centred versus Market-centred product choice" 10 may lead to the cultural entrepreneur focusing too heavily on an exchange with one of his/her potential 'customers' at the expense of another. Zeithaml \& Bitner's adapted "services marketing triangle" 11 in Exhibit Three indicates the potential for confusion or even exchange failure, due to the different roles (consumer and producer) being played by the players involved.

The model also shows how by adopting a "partnering strategy"12 which "capitalises on the skills and strengths of both principal and intermediary and engenders a sense of trust that improves the relationship", one might regard the artists as "partners". It would seem, however, that this 'partnership' is not always made on equal terms. Some interviewees were concerned about how the free exchange of content and service provision was currently restrained through 'inappropriate' relationships with record companies:

In dealing with the Majors, once you've done the big deal, you've got the job...you then become their employee... and I think it leads to a very unhealthy model - where the artist is employed by the record company to sell records.

Artist Manager

Some respondents noted that the technological advances being made in digital distribution, and through the Internet have the potential to further alter the established equilibrium between creative artists and service providers:

It is interesting that in this new age of technology there are artists who are going straight to this other model of doing it themselves...they say "why do I need those third party people - I can do it myself, without having to give my copyright away". I'm hoping we're going to get an independent SME culture out of that where there is much more interest in doing things in a business-like way. Music Industry Organisation

\footnotetext{
${ }^{9}$ Kotler, P. and Scheff, J. (1997) Standing Room Only: Strategies for Marketing the Performing Arts

${ }^{10}$ ibid

${ }^{11}$ Zeithaml, V.A and Bitner, M. J. (1996) Services Marketing

${ }^{12}$ ibid, p.359
} 


\section{Exhibit Three: Adapted Marketing Triangle}

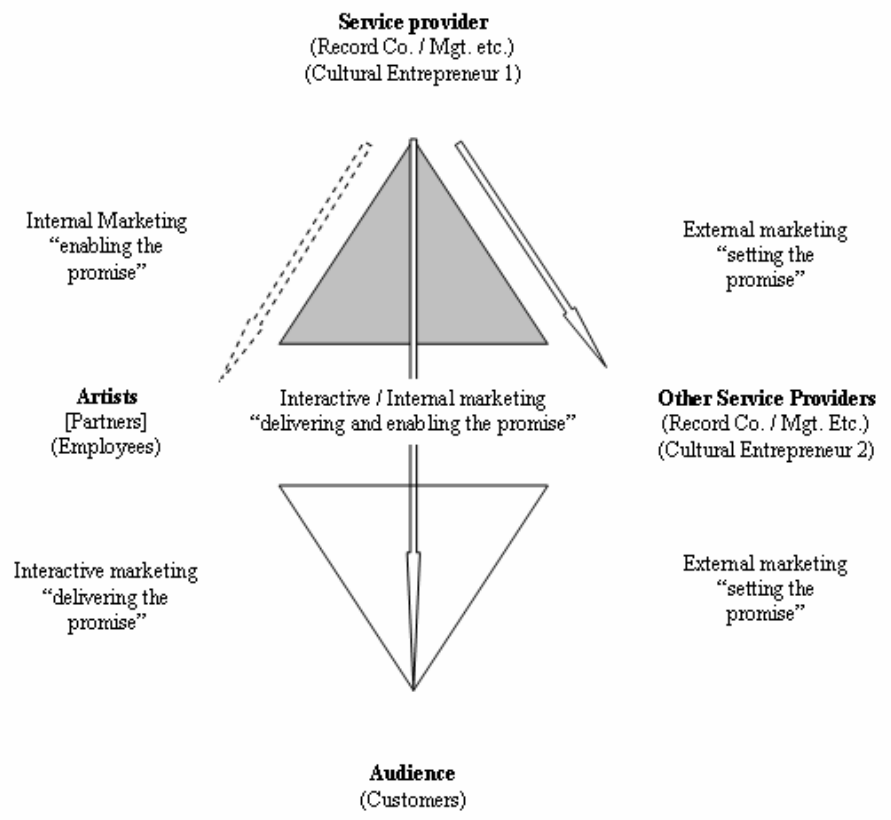

This would have the effect of bypassing the management / record companies etc. at a preliminary stage, and lead to far more than a 'blurring' of the demarcation line between consumption and production. The need for cultural entrepreneurs to adopt appropriate partnership strategies is highlighted by the comments made.

\section{ii) A blurring of the demarcation line between work and non-work}

It would be fair to say that most cultural entrepreneurs are drawn to the music industry because of their love for the music in the first instance. Where vocation transcends business, the inevitable blurring of the line between work and non-work can be seen in both a positive and negative light. The opportunity for "room for thinking and creating new ideas" has already been highlighted. However, more negatively, the assumption that music businesses are somehow not serious businesses, that they are frivolous or insignificant, has been a prevalent view that has not been easy to shake off. The public funding debate, for example, has historically polarised on a subjective appraisal of what constitutes 'high art' as opposed to other forms of art. Recently, however, the identification of the so-called 'cultural consumer', enjoying a rock concert one night followed by an opera the next, has been seen to suggest an increasingly pluralistic 'no-brow' approach to 
culture (Kolb, 2000).

The importance between striking the right balance between enthusiastic promotion and over-eager selling was an issue raised by a number of respondents:

There is also a perception of people in the music industry that because they are always seen to be selling / promoting, pushing their bands, they are automatically selling, pushing and promoting their business...and that all the information you get in terms of prospects is going to be inflated...because everyone's got the next "great artist"! Professional service provider

A significant characteristic of the music industry is its association with 'youth' and therefore, perhaps, inexperience. To some extent this has been compounded by the poor image that some high-profile artists have developed. The following observations are indicative of this potential for mistrust:

A lot of artists have difficulty in getting up in the morning, let alone heading a multinational corporation! Record Company

There may be an automatic reaction by the bank manager to age - you know, two 19 year old DJs walk in...! Professional service provider

One respondent suggested that the lack of demonstrable success could be linked to the Industry's self-perpetuated 'mystique’:

The music industry is kept mysterious...deliberately I think. There is a deliberate effort to keep it mysterious by the Majors because that's an important part of their 'magic'. The role of magic is very important in the Industry. Artist Manager The need for cultural entrepreneurs to adopt appropriate promotion strategies is highlighted by these views.

\section{(iii) The combination of individualistic values with collaborative working}

The expectation of working with others in order to fulfil the individualistic values held by cultural entrepreneurs highlights the importance of effective communication skills. The research highlighted, however, a cultural problem whereby the relationships between the music industry and finance providers were blighted by the inability to 'speak the same language': 
It is a dialogue problem - the music industry and banks don't speak the same language. Music Industry Trade Association

It's a cultural problem...there is no obvious link between people creating business and financiers...Record company

Whilst it is generally acknowledged that there is not always a 'harmony of interests' between owner-managers / investors / or sponsors ${ }^{13}$, the situation for music businesses appears to be exacerbated by the focus on the differences between the two groups, as opposed to the areas of mutual agreement. Many observers expressed the view that banks and other finance providers don't 'understand' the music industry:

I think much of the problem is a misunderstanding of who it is you are dealing with, and the value chain they are in, and how they make money.

Music Industry Organisation

According to one bank the onus fell squarely on the Industry itself to bridge this lack of understanding:

If they were half as good at promulgating their own financial infrastructure mechanisms as they are at patting themselves on the back at awards shows, then they would stand a better chance in terms of this perception of not being 'understood,. Bank

Whilst there was agreement from both the music industry itself and the finance providers that management and financial skills of business owners / managers overall have historically not been of a high standard, this was expressed with varying degrees of strength:

It is very much viewed as a 'cottage industry', with esoteric rights being marketed by people who have no clearly demonstrable financial skills. Bank

The Industry is not educated or trained enough for a lot of people starting off in it to understand how you go about licensing, and the importance of it...or the cash flow peaks and troughs... you may have to stagger from licensing deal to licensing deal just to keep going until the cash does start coming through. There are other things - there are collection societies that people don't know about (there are businesses who go and find the money on a commission basis for you, for example)...It is a communication and education issue.

Professional service provider

It was interesting to note that the online music businesses, whose management often consisted of dot.com experts as opposed to music

\footnotetext{
${ }^{13}$ See DCMS (1999) Finance Conference
} 
industry people, appeared to have less difficulty in influencing behaviour and creating beneficial exchanges with finance providers. One online music business, for example, explained how easy it had been for them to access the finance they required, precisely because they did speak the 'same' language:

Raising finance was extremely easy for us because we caught a wave, it is an exciting sector, and more than anything, the management team spoke the language of the investors. Very often in the music industry the management team doesn't have the language at all. Online music business

These findings highlight the importance of effective communication skills, which must be built on sound financial and management knowledge and experience.

\section{(iv) Being members of a wider creative community}

The extent to which "intense rivalry and competition" can operate freely in the UK music industry was held in question by many of the interviewees from the Independent sector. Often they talked of the dominant Majors in a language that was indicative of an 'us and them' culture. Indeed, one respondent suggested that the Majors themselves should not be thought of as part of the UK music industry:

We have a job of education to do, don't we? The Majors control 75\% of the market and there are four companies...none of them bank in this country...hardly any of them pay any corporation tax in this country - it is shipped off overseas through complex trading matrices - so they are not UK traders. Music Industry Organisation

The Majors' dominance of the market was felt to express itself in many ways, including the structure of the charts, the ability to gain airtime on radio, or to receive 'shop-window' marketing in the major stores. The live music circuit was seen to be "destroyed" by "too much money from the majors":

There's no live circuit now...you're either 'nothing' or you're 'big' - and that's because of the finance. If you're big then they want you to play the arenas, not theatres, and certainly not clubs. No one is interested in clubs etc. and that is a catastrophe for people learning their trade. Artist Manager

It was suggested that Independent music businesses often face substantial challenges in effectively leveraging their music assets, due to the way in which the industry operates. Interestingly, despite the 'us and them' culture 
described above, there remains a strong bond (emotionally and financially) between smaller and larger music businesses.

One owner-manager, who was offered bank finance, explained:

I went to a larger record company because I knew they would be more understanding of the dilemmas of my business and the uncertainty of the business plan. I also knew they could give me access to foreign markets, because they had established foreign territories. Record Company

The quote is also indicative of a strong flow of investment that circulates within the music industry itself. Thus, rather than looking externally towards a bank or venture capital business, many music businesses seek funding from other music businesses (often the Majors themselves). This 'self help' manifests itself at a variety of levels, including offering studio space in exchange for a share of profits from an album, through to a larger record company / distributor taking a major equity stake in a smaller label. The extent to which there is a 'choice' of finance for SMEs, however, seems to be questioned by several respondents. One interviewee commented:

There are only two forms of finance if you are in this industry - if you are a record company: i) Distributor ii) Major (or larger record company). Music Industry Organisation

The concept of 'self-help' appears to have been taken even more literally by two of the most successful Independent music businesses interviewed, both of which might be regarded as role model businesses by many others. They reported that they had never used any significant degree of external finance, either at start-up or development. As one owner commented, they had relied on "selling records!" In other words, retained profits and advances / licenses from other music companies had been sufficient. One might suggest, therefore, that cultural entrepreneurs should strive for 'selfsufficiency' over and above the self-help approach that appears characteristic of the Industry.

\section{CONCLUSION}

Whilst there are qualities of cultural entrepreneurs' approach to work that appear to promote innovation and creativity and offer lessons to other less enterprising businesses, this paper has demonstrated that such qualities are not easily defined, and carry with them inherent difficulties when attempting to 'influence behaviour'. Although this research relates to only one of the cultural industries, with its particular environment of 'radical uncertainty', 
there is a wider message for all cultural entrepreneurs at the heart of the findings: the need to reconcile the virtues of 'independence' with such qualities as appropriate partnership and promotion strategies, effective communication skills and financial self-sufficiency in order to optimise exchange conditions for cultural entrepreneurship. Such a reconciliation demands an unusual ability to combine understanding and experience of financial and management affairs with specialist music knowledge and skills. Further research would usefully identify the extent to which young practising musicians are able to affect this combination, given the increasingly high profile given to enterprise and entrepreneurship at policy level.

\section{REFERENCES}

Arts Council of England (1995), Employment in the Arts and Cultural Industries: An Analysis of the 1991 Census, London: ACE.

Brindley, P. (2000), New Music Entrepreneurs, London: IPPR.

Dane, C. (1998), The UK Record Industry Annual Survey 1998, London: Media Research Publishing.

DCMS (1999), Finance Conference: Connecting Creativity with Capital, Creative Industries Taskforce, London: DCMS.

DCMS (2000), Consumers Call the Tune, Music Industry Forum New Technology Group, London: DCMS.

Euclid (1999), Business Assistance \& Financial Investment Services on Merseyside, Banking on Culture, UK.

Feist, A., Manton, K. \& Dane, C. (1999), A Sound Performance. The Economic Value of Music to the United Kingdom, London: National Music Council.

Greaney, A. (2000), Micro Credit and the Creative and Cultural Sector, Investors in Society. A Report for Banking on Culture, Kent: IiS.

Hackett, K. and Ramsden, P. (2000), The Employment and Enterprise Characteristics of the Cultural Sector in Europe, A report for Banking on Culture, Manchester: North West Arts Board.

Kolb, B.M. (2000), Marketing Cultural Organisations. New Strategies for Attracting Audiences to Classical Music, Dance, Museums, Theatre and Opera, Dublin: Oak Tree Press.

Kotler, P. and Scheff, J. (1997), Standing Room Only: Strategies for Marketing the Performing Arts, Boston, MA: Harvard Business School Press.

Leadbeater, C. and Oakley, K. (1999), The Independents: Britain's new cultural entrepreneurs, London: Demos.

Merseyside Music Development Agency (1999), The Hidden Economy: An Economic Assessment of the Music Sector on Merseyside, Liverpool: MMDA. 
Musicians' Union (2000), Nice Work - If You Can Get It! Employment Trends for British Musicians 1978-98, London: MU.

Sibelius Academy (1998), Entrepreneurship in the Music Industry: Developing Competitiveness in the Finnish Music Industry, Research and Information Unit of the Arts Council of Finland, Helsinki: Sibelius Academy.

Smircich, L. (1983), Concepts of Culture and Organisational Analysis, Administrative Science Quarterly, 28, pp.339-58.

Westall, A. and Cowling, M. (1999), Agenda for Growth, London: IPPR.

Zeithaml, V.A. and Bitner, M.J. (1996), Services Marketing, New York: McGrawHill International. 